\title{
Influence of the Size of Coal Ash FAU Zeolites Used as Dopants on the Sensing Properties of $\mathrm{Nb}_{2} \mathrm{O}_{5}$ Thin Films
}

\author{
Katerina Lazarova ${ }^{1, *}$, Silviya Boycheva ${ }^{2}$, Marina Vasileva ${ }^{1}$, Denitza Zgureva ${ }^{3}$ and \\ Tsvetanka Babeva ${ }^{1}$ \\ 1 Institute of Optical Materials and Technologies “Acad. J. Malinowski”'Bulgarian Academy of Sciences, \\ Acad. G. Bonchev Str., bl.109, 1113 Sofia, Bulgaria; klazarova@iomt.bas.bg (K.L.), marina@iomt.bas.bg \\ (M.V.), babeva@iomt.bas.bg (T.B.) \\ 2 Technical University of Sofia, Department of Thermal and Nuclear Power Engineering, 8 Kl. Ohridsky Blvd. \\ 1000 Sofia, Bulgaria; sboycheva@tu-sofia.bg (S.B.) \\ 3 Technical University of Sofia, College of Energy and Electronics, 8 Kl. Ohridsky Blvd. 1000 Sofia, Bulgaria; \\ dzgureva@gmail.com (D.Z.) \\ * Correspondence: klazarova@iomt.bas.bg
}

Received: 13 February 2020; Accepted: 12 May 2020; Published: 13 May 2020

\begin{abstract}
In this study solid waste from coal combustion in thermal power plants (TPP) was used for synthesis of zeolite Na-X samples. They were prepared by long-term alkaline atmospheric conversion of coal ash collected from the electrostatic precipitators in TPP "AES Galabovo". When used in form of thin films/layers, optical detection of VOCs (Volatile organic compounds) is possible due to change of their reflectance spectra and color. In order to improve the sensing properties of synthesized zeolites, they were wet-milled for $60 \mathrm{~s}$ and both, milled and not - milled, were used as a dopant for the niobium oxide matrix in form of thin film deposited by the spin-coating method on silicon substrate. The surface morphology and structure of both zeolites powders were studied by scanning electron microscopy, while their size is determined from DLS (Dynamic Light Scattering) spectra. Optical constants (refractive index, $n$ and extinction coefficient, $k$ ) and thickness of the films were calculated from reflectance measurements. The change in the reflection coefficient $\Delta \mathrm{R}$ of the films was determined from measured reflectance spectra prior to and after exposure to probe acetone molecules. An increase in the reaction of the films with milled zeolites to acetone compared to the samples with not - milled zeolites is demonstrated.
\end{abstract}

Keywords: thin films; $\mathrm{Nb}_{2} \mathrm{O}_{5}$; zeolites; optical constants; sensing of acetone

\section{Introduction}

FAU (faujasite) is a rare natural zeolite which has its synthetic counterpart zeolite $X$. The sodium form of the synthetic zeolite $\mathrm{X}-\mathrm{Na}-\mathrm{X}$, is widely used because of its structural supercage with large pore size and high specific surface area [1]. The specific surface area is a dominant parameter for zeolites and it is well known that mechanical processing in ball mills can change the structure, morphology, specific surface area of zeolite-containing materials and occasionally improve their properties [2,3]. Gas adsorption, separation, ion-exchange, etc. are the usual applications for zeolites (also known as molecular sieves) due to their crystalline nature with framework-type structure built of pores with molecular dimensions [4]. Coal fly ash zeolites of FAU type (CFAZ-FAU) are easily synthesized by alkaline conversion of coal fly ash saving raw materials by utilizing solid wastes [5]. CFAZ-FAU especially have the potential and can be used for traditional application in waste water and gas purification by adsorption or separation [5-7]. Recently, novel 
advanced applications of zeolite materials have been extensively explored [1,8]. Zeolites are integrated as active media in various sensor devices $[9,10]$, zeolite film with low dielectric constant are used as isolators for computer chips [11,12], one-layer zeolite antireflective coatings are developed [13], etc. If the optical and sensing properties of thin zeolite films or doped with zeolites films can be optimized or controlled [14] precisely then practical applications are numerous. For fabrication of zeolite - based films the spin coating method is widely used among various techniques due to its advantages such as rapidity, simplicity and high uniformity of the surface of the films $[10,11,15]$. In most of the cases the synthesized zeolites when used are in form of powder, and according to our knowledge, thin films of fly ash zeolites is a novelty and is done for the first time. As we have already shown in our paper [16], one of the ways to obtain good optical quality films from powdered CFAZ-FAU is to incorporate them into a metal oxide matrix.

In this paper the optical and sensing properties toward acetone of $\mathrm{Nb}_{2} \mathrm{O}_{5}$ thin films doped with CFAZ-FAU, obtained by spin coating method, are studied. The aqueous zeolite dispersion of both wet milled for $60 \mathrm{~s}$ and not-milled CFAZ-FAU are used for dopping the $\mathrm{Nb}$ sol prior to deposition of the films. Three different concentrations of dopants are prepared $-1,2.5$ and $5 \%$ for both types (milled and not - milled). The influence of the size of CFAZ- FAU on the sensing properties of metal oxide thin films is studied and demonstrated. Besides, the possibility of controlling the thickness $(d)$ and refractive index $(n)$ of the films through variation of concentration or size of zeolites is investigated.

\section{Materials and Methods}

For the synthesis of CFAZ-FAU, as a starting material fly ash is used. Solid waste ash is collected from coal combustion in "AES Galabovo" thermal power plant (TPP), one of the biggest in Bulgaria, which is supplied by domestic lignite coal from the "Maritza East" basin. Synthesized $\mathrm{Na}-\mathrm{X}$ phase zeolite powder samples are prepared by long-term alkaline atmospheric conversion. At this conversion approach slurries of coal fly ash in $1.5 \mathrm{~mol} / \mathrm{l} \mathrm{NaOH}$ were incubated continuously at room conditions. Detailed method of synthesis and characterization of zeolites is described in [17].

Zeolites, obtained after the synthesis in the form of powder, are subjected to wet-milling with a PULVERISETTE 23 Mini-Ball Mill (FRITSCH) for $60 \mathrm{~s}$ in $50 \mathrm{osc} / \mathrm{min}$ as $0.08 \mathrm{~g}$ CFAZ-FAU powder and $3 \mathrm{~mL}$ distilled water are used. The size of zeolites is determined from DLS (Dynamic Light Scattering) spectra measured by Zetasizer Nano ZS (Malvern), while their morphology is studied by Philips 515 electron microscope.

For the deposition of metal oxide thin films is used $\mathrm{Nb}$ sol, prepared by sonocatalytic method according to the recipe described in [18]: $0.400 \mathrm{~g} \mathrm{NbCl}_{5}$ (99\%, Aldrich) precursor mixed with $8.3 \mathrm{~mL}$ ethanol (98\%, Sigma-Aldrich) and $0.17 \mathrm{~mL}$ distilled water. The obtained solution is subjected to sonification for $30 \mathrm{~min}$ and aged for $24 \mathrm{~h}$ at ambient conditions prior to spin coating. Three different concentrations of $\mathrm{Nb}$ sol dopped with milled and not-milled zeolites $\left(\mathrm{Nb}_{2} \mathrm{O}_{5}-\mathrm{CFAZ}\right.$-FAU) are prepared $-1,2.5$ and 5\%. Initially, the selected amount of zeolites from the aqueous solution and small amount of ethanol is mixed, and then added to the corresponding amount of $\mathrm{Nb}$ sol in order to keep the mixture clear.

Thin $\mathrm{Nb}_{2} \mathrm{O}_{5}$ - CFAZ-FAU films are deposited by spin coating method at a rate of $4000 \mathrm{rpm}$ for 60 $\mathrm{s}$ by dropping of $0.3 \mathrm{~mL}$ of the sol/zeolite solution on pre-cleaned Si substrates. After deposition, the films are annealed in air at $320{ }^{\circ} \mathrm{C}$ for $30 \mathrm{~min}$. CARY 05E UV-VIS-NIR spectrophotometer with accuracy of $0.3 \%$ is used for the measurements of reflectance spectra of the films in order to study their optical properties. The thickness $(d)$ and optical constants - refractive index $(n)$ and extinction coefficient $(k)$, are determined from measured reflectance spectra of the films at normal light incidence using non-linear curve fitting method [19] with experimental errors for $n, k$ and $d$ respectively $0.005,0.003$ and $2 \mathrm{~nm}$. All $n$ and $k$ values are taken at wavelength $600 \mathrm{~nm}$. In order to study the sensing properties of the $\mathrm{Nb}_{2} \mathrm{O}_{5}$-CFAZ-FAU films reflectance spectra is measured in the same spot prior to and after exposure to liquid acetone by using Zeta-20 (Zeta Instruments) optical profiler with a built-in spectrometer. 


\section{Results and Discussion}

\subsection{Zeolite Size}

The DLS analysis is performed to determine the hydrodynamic diameter and particle size distribution of the zeolite particles before and after the wet milling along with SEM (scanning electron microscope) examination of powder samples. The selected wet-milling time of $60 \mathrm{~s}$ is based on not reported previous preliminary experiments with $\mathrm{Na}-\mathrm{X}$ zeolites subjected to mechanical processing in ball mills for a period of $30 \mathrm{~min}$. Experiment shows deterioration of the optical quality of metal oxide films after dopping with milled zeolites and change of the reflectance spectra $\Delta \mathrm{R}$ when exposed to liquid acetone at about $1.4 \%$. According to the theoretical curve of developed specific surface as a function of grinding time $[20,21]$ three well-shaped areas can be observed: 1) Rittinger-zone: the increase of the specific surface is proportional to the grinding time; 2) Aggregation-zone: intensity of specific surface growth is decreasing by grinding time; 3) Agglomeration-zone: the specific surface decreases with the comminution time. Depending on the type of zeolite, the time corresponding to the different stages is different [21]. In the light of this and our results we have chosen a short milling period - $60 \mathrm{~s}$.

Figure 1 shows the result of the DLS measurement and indicated a relatively narrow distribution of particle size with an average crystal size of $1470 \mathrm{~nm}\left(\mathrm{~d}_{1}\right)$ prior to milling of the zeolites obtained directly after synthesis.

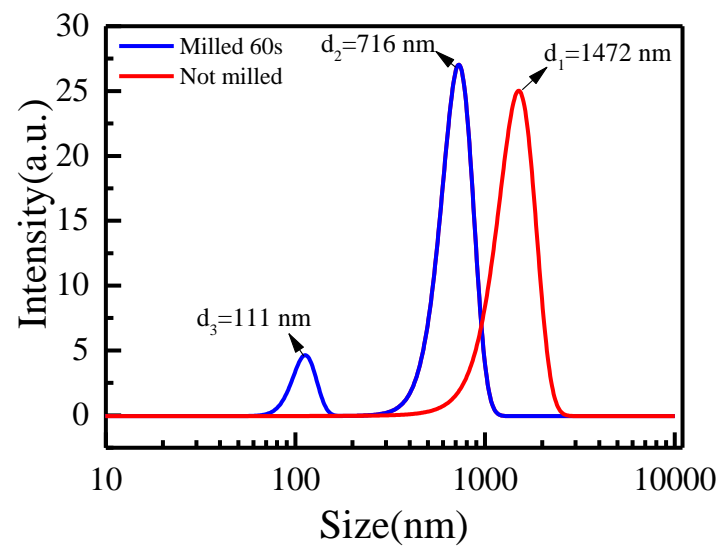

Figure 1. Distribution of particle size of CFAZ-FAU (Na-X) before (red curve) and after (blue curve) wet-milling for $60 \mathrm{~s}$.

This result is consistent with the results obtained by the Tao Hu et al. in [22] according to which the average crystal size of $\mathrm{Na}-\mathrm{X}$ zeolites synthesized from coal fly ash, estimated using the cumulative distribution method, ranges from 1 to $2 \mu \mathrm{m}$. From our previous studies with not-milled zeolites [16], we have found that zeollites having this size impairs the optical quality of the films. After wet-milling for $60 \mathrm{~s}$, the size decreases and the particle size distribution changes from monomodal in the case of non-milled zeolites to bimodal for milled samples. The two peaks are centered at $\mathrm{d}_{2}=716 \mathrm{~nm}$ and $\mathrm{d}_{3}=111 \mathrm{~nm}$. Smaller particles size implies reducing the scattering and an improvement in the optical quality compared to $\mathrm{Nb}_{2} \mathrm{O}_{5}$ dopped with not-milled zeolites. Besides, an enhancement of the sensing properties due to increasing of specific surface area could be expected. M. Fathizadeha et al. synthesize by hydrothermal method Na-X-type zeolites, with the size of 112 $\mathrm{nm}$ [23], proven by the DLS method, which is in accordance with our results.

Figure 2 shows SEM pictures of not-milled $(a, c)$ and milled for $60 \mathrm{~s}(\mathrm{~b}, \mathrm{~d})$ powder fly ash zeolites at two different magnifications - 5000× $(\mathrm{a}, \mathrm{b})$ and $10000 \times(\mathrm{c}, \mathrm{d})$, respectively. Agglomerations of indistinguishable particles are observed before milling and octahedral shape crystallites typical of the FAU phase. Inclusions of particles from other zeolite phases are also found, which often 
accompany the crystallization of FAU from coal fly ash [17]. After the mechanical processing, a clear separation of the individual particles of about 1-1.5 $\mu \mathrm{m}$ size is observed.
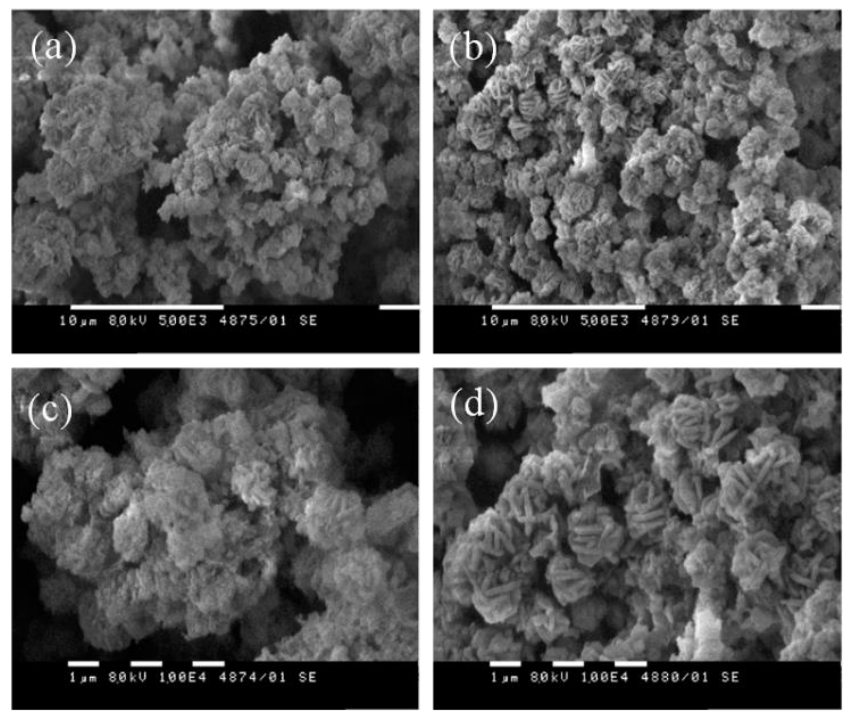

Figure 2. SEM pictures of not-milled $(\mathbf{a}, \mathbf{c})$ and milled for $60 \mathrm{~s}(\mathbf{b}, \mathbf{d})$ fly ash zeolites powders at magnification $5000 \times(\mathbf{a}, \mathbf{b})$ and $10000 \times(\mathbf{c}, \mathbf{d})$.

The two sizes of powdered zeolites are used for dopping the thin niobium oxide films in three different concentrations $-1,2.5$ and $5 \%$. Reflectance spectra of the films are measured in order to study their optical properties and to calculate the thickness. Figure 3 presents measured reflectance spectra of $\mathrm{Nb}_{2} \mathrm{O}_{5}$ films dopped with milled zeolites (a) and dependence of thickness d on zeolite concentration (b) of thin $\mathrm{Nb}_{2} \mathrm{O}_{5}$ films embedded with not-milled (red line) and milled (black line) fly ash FAU zeolites.
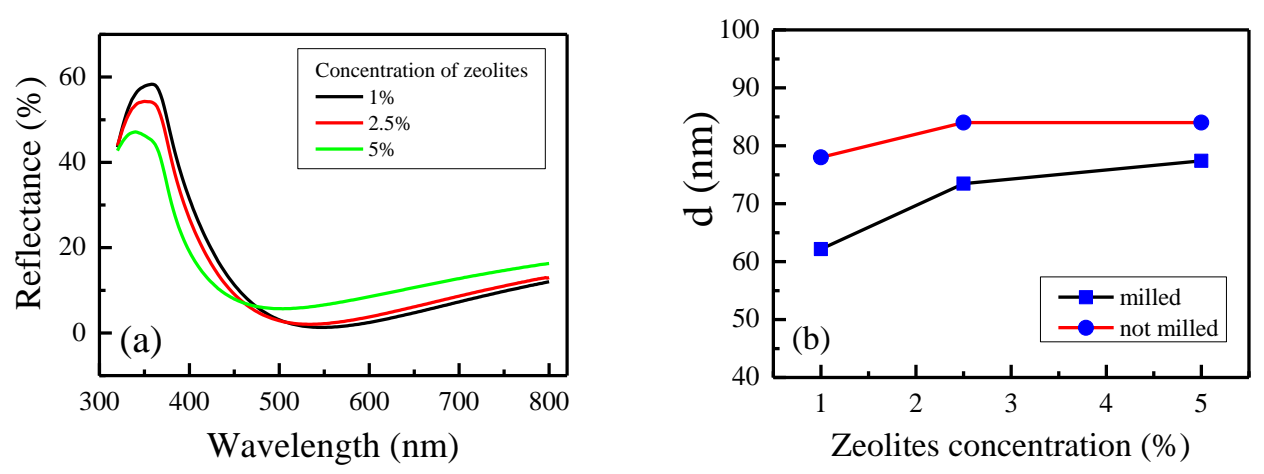

Figure 3. Reflectance spectra of $\mathrm{Nb}_{2} \mathrm{O}_{5}$ films with milled zeolites (a) and dependence of thickness $d$ on zeolite concentration (b) of thin $\mathrm{Nb}_{2} \mathrm{O}_{5}$ films embedded with not-milled and milled fly ash FAU zeolites.

It is seen from Figure 3a that spectra shifts towards shorter wavelengths mostly pronounced for the film doped with $5 \mathrm{wt} \%$. Considering that reflectance is periodic function of optical thickness (the product of refractive index and film thickness) a decrease in optical thickness could be expected with doping. In order to verify this assumption the thickness $\mathrm{d}$ and refractive index $\mathrm{n}$ are calculated from measured reflectance spectra of the films. At Figure $3 b$ it is seen that the two d-vs-concentration curves are very similar and both have a slight change in thickness with increasing zeolite concentration, more pronounced and evenly in the films with milled particles. As shown, films doped with not-milled zeolites have thickness around $78 \mathrm{~nm}-80 \mathrm{~nm}$ for $1 \%$ concentration and there is a slight increase in $d$ at concentrations of 2.5 and 5\%, which is the same in both cases $-84 \mathrm{~nm}$. The films with milled zeolites have clear tendency of increasing thickness with concentration of zeolites - 
from 62, 73 and $77 \mathrm{~nm}$ for 1, 2.5 and $5 \%$ respectively. Bearing in mind that the films are deposited from the same amount of $\mathrm{Nb}$ sol and zeolites for each concentration, the difference observed in $\mathrm{d}$ is only due to the different particle sizes for milled and not-milled zeolites. Thus, by using smaller zeolites, we can more precisely control and obtain thin films with a specific thickness, as needed. Also, this applies to the control of the refractive index of the films which is very important in terms of depositing 1D photon crystals for example where layers with exact $\mathrm{d}$ and $\mathrm{n}$ are needed in order to obtain optical contrast and achieve reflectance band gap [24].
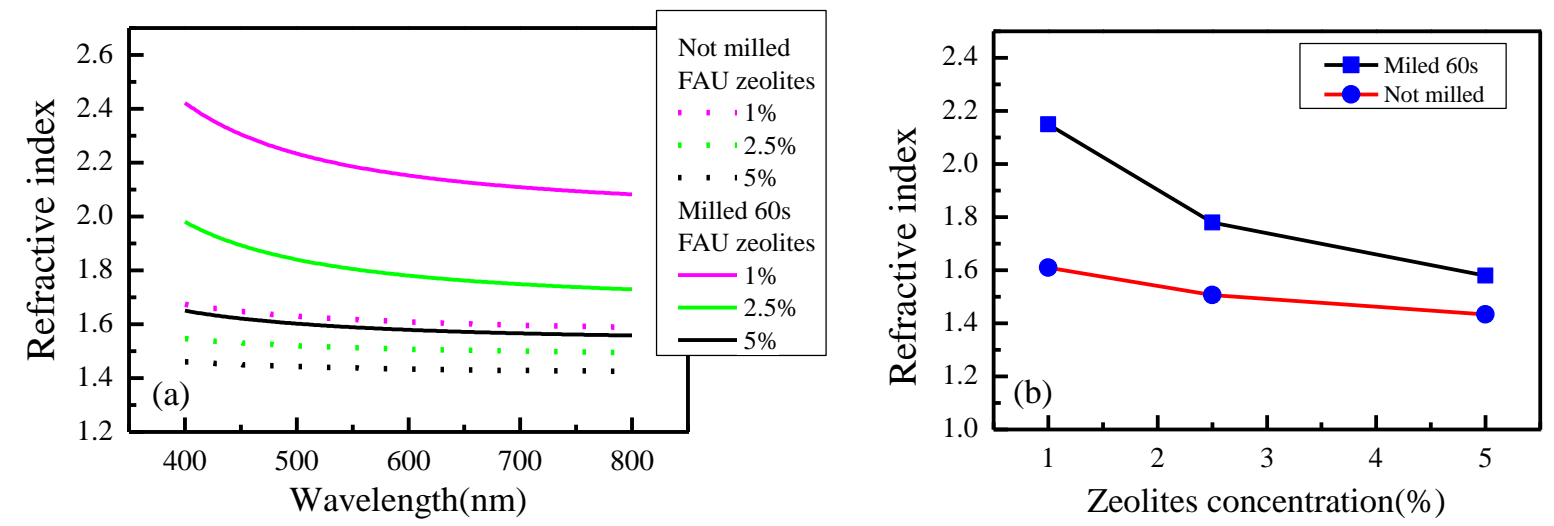

Figure 4. Dispersion curves of refractive index (a) and dependence of refractive index $n$ at wavelength of $600 \mathrm{~nm}$ of zeolite concentration (b) of thin $\mathrm{Nb}_{2} \mathrm{O}_{5}$ films embedded with not-milled and milled fly ash FAU zeolites.

Dispersion curves of refractive index of thin $\mathrm{Nb}_{2} \mathrm{O}_{5}$ films doped with not - milled and milled fly ash FAU zeolites and the dependence of refractive index $\mathrm{n}$ on zeolite concentration are shown in Figure 4. Generally films with milled zeolites have higher refractive index as compared to films doped with not - milled zeolites. Considering that $\mathrm{n}$ is directly proportional to the density of films, we could conclude that films doped with milled zeolites have higher density. Because of smaller size of milled zeolites their packing density in the niobia matrix is higher resulting in lower thickness (Figure 3b), higher density and refractive index as compared to samples doped with not - milled zeolites. Further, for samples with milled zeolites a clearer and more pronounced decrease in $n$ is observed with increasing the zeolite concentration. This is expected since the zeolites themselves are a material with a low refractive index $(n=1.466-1.480)$ and their addition to a material with high $n$ (such as $\mathrm{Nb}_{2} \mathrm{O}_{5}, \mathrm{n} \approx 2.20$ ) [19] results in a decrease in the value of $\mathrm{n}$ of the composite thin film. The value of $\mathrm{n}$ for a $1 \%$ concentration of milled zeolites is 2.15 , which is very close to $\mathrm{n}$ of a pure film of $\mathrm{Nb}_{2} \mathrm{O}_{5}$ and at 2.5 and $5 \%$ concentration $\mathrm{n}$ is respectively 1.8 and 1.6. From Figure 4 is also seen that films with not-milled zeolites have lower $n$ ranging 1.43 - 1.6. All samples have normal dispersion curves. It can be seen that by doping with different zeolites concentrations and sizes we can obtain composite material with a refractive index varying in a wide range - from 2.15 to 1.43 .

By adding zeolites to metal oxide matrix we could assume that the overall porosity of $\mathrm{Nb}_{2} \mathrm{O}_{5}$ matrix increases and this is confirmed by the observed reduction in effective refractive index. In addition to the microporosity of the zeolites it is possible also additional free volume (air) to be introduced in the samples which volume fraction is different depending on concentration and size of FAU particles. Both zeolites and air $(n=1.0003)$ contribute to decrease of the effective refractive index of doped films. Higher porosity/free volume is a prerequisite for stronger absorption in to micro - and mesopores of the films when exposed to liquid analyte, thus controlling the sensing properties.

To verify this we measure reflectance spectra for composite thin films before and after immersion in liquid acetone for $5 \mathrm{~min}$ and calculate induced change in reflectance $\Delta \mathrm{R}$ for both films with milled and not-milled zeolites (Figure 5). The addition of not-milled zeolites results in a $1.6-2.5$ $\%$ change in $\Delta \mathrm{R}$ as increase of concentration leads to decrease of reflectance change. The opposite is true in the case of films with smaller zeolite particles - as the amount of zeolites increases, the change 
in the reflection coefficient increases from 7.6, 9.3 to 19.4. In addition, a maximum change of nearly $20 \%$ was achieved, compared to $2.5 \%$ for the non-milled samples.

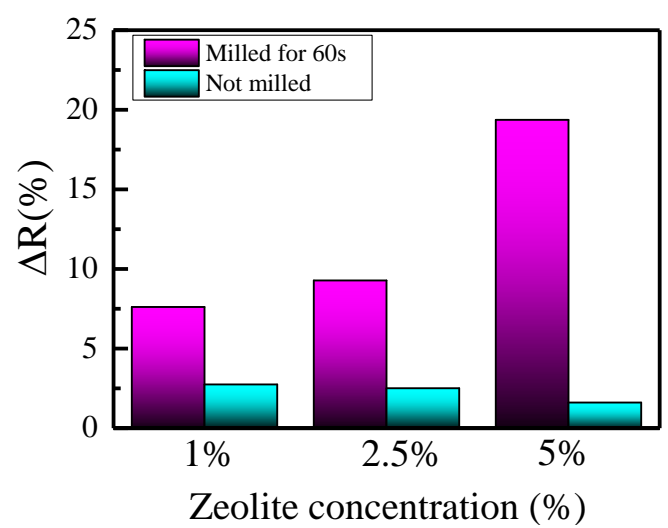

Figure 5. Zeolite concentration dependence of reflectance change induced by exposure to liquid acetone of CFAZ-FAU not-milled (blue bars) and milled (magenta bars) embedded in thin $\mathrm{Nb}_{2} \mathrm{O}_{5}$ films. Measurements are conducted at room temperature.

In order to check the selectivity of the films, similar measurements are made with liquid ethanol for films with milled zeolites. Ethanol was selected as probing liquid because its refractive index is similar to this of acetone: 1.361 and 1.359 are respective refractive indices of ethanol and acetone at wavelength of $600 \mathrm{~nm}$ [25]. As can be seen from Figure 6, the change in the reflection coefficient $\Delta R$ due to ethanol exposure is on average about $2.5 \%$ without pronounced concentration dependence. This means that the optical response toward ethanol is almost 8 times weaker as compared to acetone. Considering the similarity of refractive index we may conclude that a significantly smaller amount of ethanol is absorbed in the films as compared to acetone. The possible reason is the different impact of polarity, surface energy, hydrophilicity/hydrophobicity, etc. on the analyte absorption.

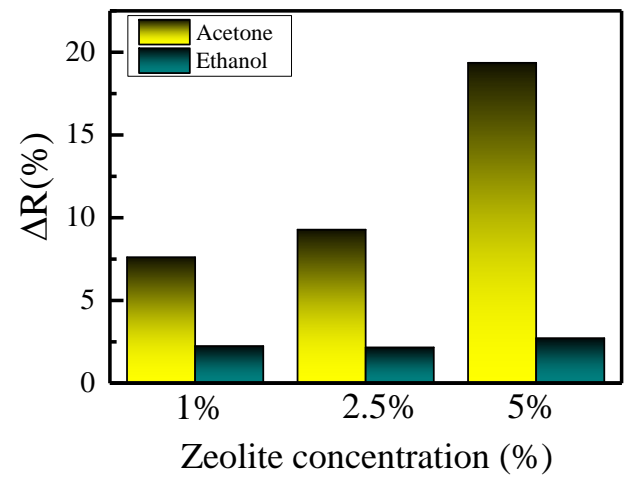

Figure 6. Zeolite concentration dependence of reflectance change induced by exposure to liquid acetone (yellow) and ethanol (green) of milled CFAZ-FAU embedded in thin $\mathrm{Nb}_{2} \mathrm{O}_{5}$ films. Measurements are conducted at room temperature.

\section{Conclusions}

FAU zeolites of coal ash with a particle size of $1470 \mathrm{~nm}$ have been synthesized by alkaline atmospheric conversion. The possibility of reducing their size in half and also obtain particles of about $100 \mathrm{~nm}$ size by wet milling has been demonstrated. Successfully have been deposited composite thin films comprising $\mathrm{Nb}_{2} \mathrm{O}_{5}$ matrix and fly ash FAU zeolites in concentrations from 1 to 5 $\%$ with good optical quality and reflectance coefficient in range $47-58 \%$. The possibility of controlling the refractive index and sensing properties of the films with milled zeolites through 
variation of concentration and size of particles is shown. The value of $n$ varies in a wide range from 2.2 to 1.8 and 1.6. The presence of porosity is verified and confirmed by reflectance coefficient change of the films before and after exposure to liquid acetone and ethanol thus confirming also selectivity toward acetone. The maximum liquid-induced changes for samples with milled zeolites are eight times higher that change in films dopped with not-milled zeolites and dependence of reflectance change of concentration is proved for films with small FAU particles. Thin films with milled zeolites shows change in reflectance induced from acetone $20 \%$ compared to $2.7 \%$ change after exposure to liquid ethanol at same concentration (5\%).

Author Contributions: conceptualization, K.L., T.B. and S.B.; methodology, K.L. and T.B.; software, K.L. and T.B.; validation, K.L.,T.B. and S.B.; formal analysis, K.L., D.S. and M.V.; investigation, K.L., D.S. and M.V.; resources, S.B. and T.B.; writing - original draft preparation, K.L.; writing-review and editing, K.L., T.B. and S.B.

Funding: This research received no external funding.

Acknowledgments: The financial support of Bulgarian National Science Fund (BNSF) under the project DN 17/18 (12.12.2017) is highly appreciated. Research equipment of distributed research infrastructure INFRAMAT (part of Bulgarian National roadmap for research infrastructures) supported by Bulgarian Ministry of Education and Science under contract D01-284/17.12.2019 was used in this investigation. The assistance of Prof. Vera Marinova from IOMT-BAS in the process of zeolite milling is highly appreciated.

Conflicts of Interest: The authors declare no conflict of interest.

\section{References}

1. Goldyn, K.; Anfray, C.; Komaty, S.; Ruaux, V.; Hélaine, C.; Retoux, R.; Valable, S.; Valtchev, V.; Mintova. S. Copper exchanged FAU nanozeolite as non-toxic nitric oxide and carbon dioxide gas carrier. Microporous Mesoporous Mater. 2019, 280, 271-276.

2. Nikashina, V.A.; Streletskii, A.N.; Kolbanev, I.V.; Meshkova, I.N.; Grinev, V.G.; Serova, I.B.; Yusupov, T.S.; Shumskaya, L.G. Effect of mechanical activation on the properties of natural zeolites. Inorg. Mater. 2011, 47, 1341-1346.

3. Buzimov, A.Y.; Kulkov, S.N.; Kurovics, E.; Eckl, W.; Pappert, S. Influence of mechanical activation on the properties of natural zeolites from Tokaj Mountain. IOP Conf. Ser. Mater. Sci. Eng. 2017, 175, 012033.

4. Kianfar, E. Nanozeolites: Synthesized, properties, applications. J. Sol-Gel Sci. Technol. 2019, 91(2), 415-429.

5. Querol, X.; Moreno, N.; Umaña, J.C.; Alastuey, A.; Hernández, E.; López-Soler, A.; Plana, F. Synthesis of zeolites from coal fly ash: An overview. Int. J. Coal. Geol. 2002, 50, 413-423.

6. Querol, X.; Moreno, N.; Umaña, J.C.; Juan, R.; Hernández, S.; Fernandez-Pereira, C.; Ayora, C.; Janssen, M.H.M.; García-Martínez, J.; Linares-Solano, A.; Cazorla-Amoros, D. Application of zeolitic material synthesised from fly ash to the decontamination of waste water and flue gas. J. Chem. Technol. Biotechnol. 2002, 77, 292-298.

7. Boycheva, S.; Zgureva, D.; Václavíková, M.; Kalvachev, Y.; Lazarova, H.; Popova, M. Studies on non-modified and copper-modified coal ash zeolites as heterogeneous catalysts for VOCs oxidation. J. Hazard Mater. 2019, 361, 374-382.

8. Bein, T.; Mintova, S. Advanced applications of zeolites. Stud. Surf. Sci. Catal. 2005, 157, 263-288.

9. Xu, X.; Wang, J.; Long, Y. Zeolite-based Materials for Gas Sensors. Sensors 2006, 6(12), 1751-1764.

10. Zheng, Y.; Li, X.; Dutta, P.K. Exploitation of Unique Properties of Zeolites in the Development of Gas Sensors. Sensors 2012, 12(4), 5170-5194.

11. Wang, Z.B.; Wang, H.T.; Mitra, A.; Huang, L.M.; Yan, Y.S. Pure-Silica Zeolite Low-k Dielectric Thin Films. Adv. Mater. 2001, 13, 746-749.

12. Mintova, S.; Reinelt, M.; Metzger, T.H.; Senker, J.; Bein, T. Ordered Porous Solids: Recent Advances and Prospects. Chem. Commun. 2003, 3, 326.

13. Chen, C.H.; Li, S.-Yi.; Chiang, A.S.T.; Wu, A.T.; Sun, Y.S. Scratch-resistant zeolite anti-reflective coating on glass for solar applications. Sol. Energ. Mat. Sol. Cells 2011, 95(7), 1694-1700.

14. Lazarova, K.; Awala, H.; El Fallah, J.; Vassileva, M.; Mintova, S.; Babeva,T. Optimization of optical and sensing properties of sol-gel oxides through zeolite doping. Bulg. Chem. Commun. 2017, 49(F), 88-94. 
15. Mintova, S.; Bein, T. Microporous Films Prepared by Spin-Coating Stable Colloidal Suspensions of Zeolites. Adv. Mater. 2001, 13(24), 1880-1883.

16. Lazarova, K.; Boycheva, S. V.; Vasileva, M.; Zgureva, D.; Georgieva, B.; Babeva, T. Zeolites from fly ash embedded in thin niobium oxide matrix for optical and sensing applications. J. Phys. Conf. Ser. 2019, 1186:012024.

17. Zgureva, D.; Boycheva, S.; Behunova, D.; Václaviková, M. Smart and zero-energy utilization of coal ash from Thermal Power Plants in the context of circular economy and related to soil recovery. Asce J. Environ. Eng. 2020, 146, accepted for publication.

18. Arfsten, N.J.; Gavlas, J.F. Us Pat. 2004, 6811901 B1.

19. Lazarova, K.; Vasileva, M.; Marinov, G.; Babeva, T. Optical characterization of sol-gel derived $\mathrm{Nb}_{2} \mathrm{O}_{5}$ thin films. Opt. Laser Technol. 2014, 58, 114-118.

20. Opoczky, L. Fine grinding and agglomeration of silicates. Powder Technol. 1977, 17, 1-7.

21. Mucsi, G. Mechanical activation of power station fly ash by grinding - A review. J. Silic. Based Compos. Mater. 2016, 68, 56-61.

22. Hu, T.; Gao, W.; Liu, X.; Zhang, Y.; Meng, C. Synthesis of zeolites Na-A and Na-X from tablet compressed and calcinated coal fly ash. R. Soc. Open Sci. 2017, 4170921.

23. Fathizadeh, M.; Aroujalian, A. Synthesis and Characterization of Nano Particle Crystals of NaX Zeolite. Int. J. Ind. Chem. 2011, 2(3), 140-143.

24. Babeva, T.; Awala, H.; Vasileva, M.; Fallah, J.E.; Lazarova, K.; Thomas, S.; Mintova, S. Zeolite films as building blocks for antireflective coatings and vapor responsive Bragg stacks. Dalton Trans. 2014, 43, 8868-8876.

25. Rheims, J.; Köser, J.; Wriedt, T. Refractive-index measurements in the near-IR using an Abbe refractometer. Meas. Sci. Technol 1997, 8, 601-605.

(C) 2020 by the authors. Submitted for possible open access publication under the terms and conditions of the Creative Commons Attribution (CC BY) license (http://creativecommons.org/licenses/by/4.0/). 